\title{
Accessory Mental Foramen Misdiagnosed as Radiolucent Tumour by Conventional Dental Radiography
}

\author{
Shoko Gamoh"1, Yui Mori'2,3, Michiko Nakatsuka4, Hironori Akiyama1, Yumiko Ogawa5, \\ Yasutomo Iwai ${ }^{4}$, Shosuke Morita ${ }^{5}$, Kimishige Shimizutani ${ }^{1}$ \\ ${ }^{1}$ Department of Oral Radiology, Osaka Dental University, Osaka, Japan \\ ${ }^{2}$ Department of Dentistry, Sumitomo Hospital, Osaka, Japan \\ ${ }^{3}$ Second Department of Oral and Maxillofacial Surgery, Osaka Dental University, Osaka, Japan \\ ${ }^{4}$ Department of Oral Anatomy, Osaka Dental University, Osaka, Japan \\ ${ }^{5}$ First Department of Oral and Maxillofacial Surgery, Osaka Dental University, Osaka, Japan \\ Email: shoko1105@gmail.com
}

Received 11 March 2014; revised 11 April 2014; accepted 18 April 2014

Copyright (C) 2014 by authors and Scientific Research Publishing Inc.

This work is licensed under the Creative Commons Attribution International License (CC BY).

http://creativecommons.org/licenses/by/4.0/

c) (i) Open Access

\section{Abstract}

The mental foramen is an important landmark for identifying the mental nerve, and the accessory mental foramen is a rare anatomical variation. This article describes the use of computed tomography (CT) to detect an accessory mental foramen that was initially misdiagnosed as a radiolucent tumour in the right premolar region of a 39-year-old woman by panoramic radiography. The case suggests that preoperative CT should be performed to detect any anatomical variations. This knowledge would help in diagnosis, preoperative planning and prevention of intraoperative nerve or vascular injury.

\section{Keywords}

Accessory Mental Foramen, Mandibular Nerve, Panoramic Radiography, Computed Tomography

\section{Introduction}

The mental foramen is located on the anterolateral aspect of the mandible, 13 - $15 \mathrm{~mm}$ superior to the inferior border of the mandibular body, and oriented outwards and upwards [1]. Radiographically, it appears as a single circular or elliptical radiolucent area in the premolar region. Absence of the mental foramen [2] and presence of multiple mental foramens [3] are rarely reported. One reason may be difficulty in observation by conventional 
dental radiographic techniques, such as panoramic radiography, because the long axis of the accessory mental foramen is generally shorter than $1.5 \mathrm{~mm}$ [4].

CT provides detailed information about maxillofacial structures and allows extensive evaluation of their topography. It is supposed to be the most accurate imaging modality for identification and localization of the mandibular foramen, mandibular canal and mental foramen [5]. This article describes the use of CT to detect an accessory mental foramen that was initially misdiagnosed as a radiolucent tumour by panoramic radiography.

\section{Case Report}

A 39-year-old asymptomatic woman was referred to our institution because of a radiolucent area found in the mandible by routine panoramic radiography. The patient had no particular subjective symptoms. The radiolucency had been misdiagnosed as a tumour in a private dental clinic. The panoramic radiograph (Figure 1(a)) and intraoral panoramic radiograph (Figure 1(b)) obtained at our department, which were examined by an oral and maxillofacial radiologist with 10 years of experience in imaging diagnosis, did not reveal abnormality.

CT was performed in accordance with the patient's wishes. Axial slices of the mandible were obtained with the bone filter of the scanner (Bright Speed Elite, GE Healthcare, Milwaukee, WI). The slice thickness, pitch and tube voltage were $0.65 \mathrm{~mm}, 0.625: 1$ and $120 \mathrm{kV}$, respectively; the electrical current was automatically optimised for the object thickness (maximum, $120 \mathrm{~mA}$ ). Sagittal and coronal slices (1 mm thickness) were reformatted and reconstructed in the right premolar region (Figure 2). The resultant image showed an accessory mental foramen, without any lesion, in the right premolar region. Bifurcation of the mandibular canal between the premolars was also evident.

\section{Discussion}

Riesenfeld was the first to describe the accessory mental foramen in 1956 [6]. Since then, other anatomical variations such as the mandibular incisive canal, anterior loop and bifid mandibular canal have been reported. Twodimensional radiographs, such as intraoral and panoramic radiographs, are limited by geometric projection of structures [7], and are not entirely reliable for preoperative planning [8]. CT can help to detect anatomical variations missed by conventional imaging [9], as in the presented case.

The possible reasons for misdiagnosis are as follows. The cortical bone in the mandibular premolar region is

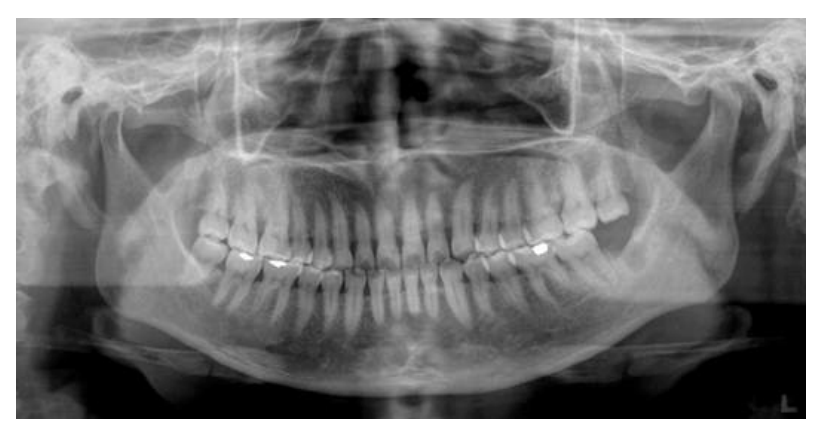

(a)

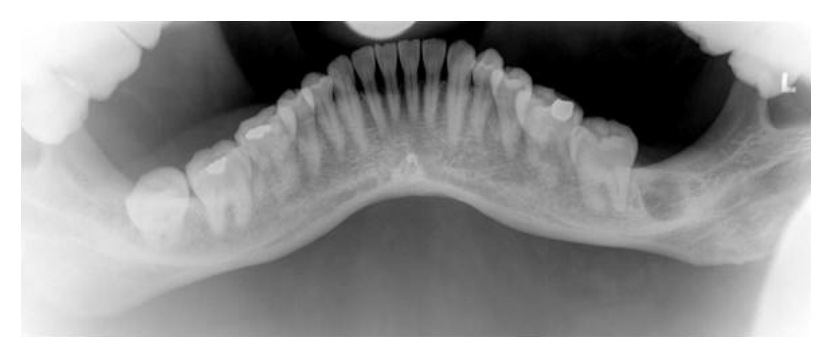

(b)

Figure 1. Initial radiographic findings. (a) Panoramic radiograph and (b) intraoral panoramic radiograph. Neither image demonstrates the accessory mental foramen. 


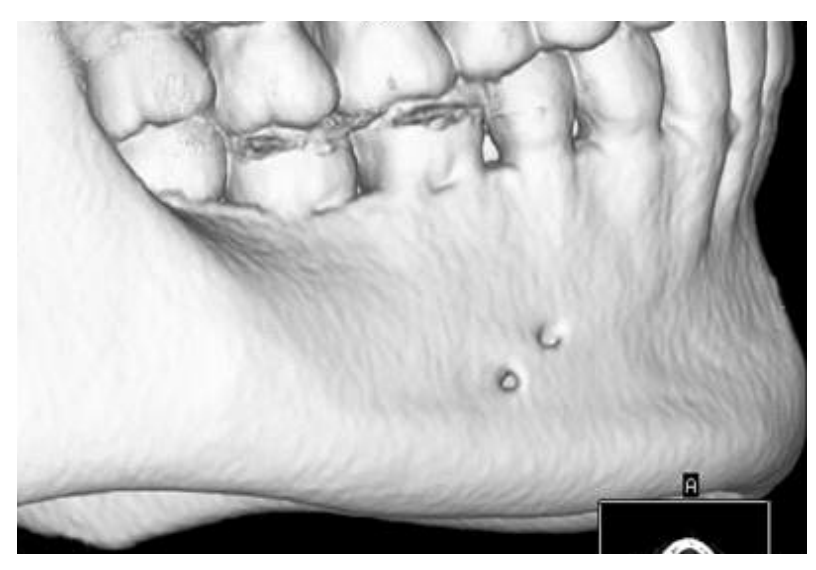

Figure 2. Three-dimensional reconstructed CT image showing the accessory mental foramen in the right premolar region.

concave because of the submandibular and sublingual fossae, which appear radiolucent. Further, the mental and accessory mental foramens mimic radiolucent lesions. Finally, the long axis of the accessory mental foramen in the presented case was $2 \mathrm{~mm}$, longer than the standard length [4] [8].

A search of the PubMed and Scopus databases by using the entry term "accessory mental foramen" revealed 31 and 47 relevant articles, respectively, with reported incidence rates of $10.5 \%$ [10], 11.3\% [8] and 10\% [11]. The incidence rate varies by ethnicity from $1.4 \%$ to $9.7 \%$ [10]. The prevalence rate ranges from $6.7 \%$ to $12.5 \%$ in Japan [4]. No previous study showed gender differences [4] [11]. The patient in the presented case was a woman.

The mental foramen is completely formed by the 12th gestational week, when the mental nerve separates into several fasciculi at that site [12]. Separation of the mental nerve before formation of the mental foramen could lead to formation of accessory mental foramens [13]. Optimal knowledge of the local anatomy and preoperative radiographic identification of anatomical variations are important because nerve injury during surgical procedures in this area can cause anaesthesia or paraesthesia [14]. The increasing use of multi-slice CT should help in avoiding misdiagnosis of bone lesions and preventing nerve and vascular injury during surgical procedures in the chin region.

\section{References}

[1] Haghanifar, S. and Rokouei, M. (2009) Radiographic Evaluation of the Mental Foramen in a Selected Iranian Population. Indian Journal of Dental Research, 20, 150-152. http://dx.doi.org/10.4103/0970-9290.52886

[2] de Freitas, V., Madeira, M.C., Toledo Filho, J.L. and Chagas, C.F. (1979) Absence of the Mental Foramen in Dry Human Mandibles. Acta Anatomica (Basel), 104, 353-355. http://dx.doi.org/10.1159/000145083

[3] Kaufman, E., Serman, N.J. and Wang, P.D. (2000) Bilateral Mandibular Accessory Foramina and Canals: A Case Report and Review of the Literature. Dentomaxillofacial Radiology, 29, 170-175. http://dx.doi.org/10.1038/sj.dmfr.4600526

[4] Toh, H., Kodama, J., Yanagisako, M. and Ohmori, T. (1992) Anatomical Study of the Accessory Mental Foramen and the Distribution of Its Nerve. Okajimas Folia Anatomica Japonica, 69, 85-88. http://dx.doi.org/10.2535/ofaj1936.69.2-3_85

[5] Igarashi, C., Yamamoto, A., Morita, Y. and Tanaka, M. (2004) Double Mental Foramina of the Mandible on Computed Tomography Images: A Case Report. Oral Radiology, 20, 68-71. http://dx.doi.org/10.1007/s11282-004-0012-1

[6] Riesenfeld, A. (1956) Multiple Infraorbital, Ethmoidal, and Mental Foramina in the Races of Man. American Journal of Physical Anthropology, 14, 85-100. http://dx.doi.org/10.1002/ajpa.1330140122

[7] Angelopoulos, C., Thomas, S.L., Hechler, S., Parissis, N. and Hlavacek, M. (2008) Comparison between Digital Panoramic Radiography and Cone-Beam Computed Tomography for the Identification of the Mandibular Canal as Part of Presurgical Dental Implant Assessment. Journal of Oral and Maxillofacial Surgery, 66, 2130-2135. http://dx.doi.org/10.1016/j.joms.2008.06.021

[8] Katakami, K., Mishima, A., Shiozaki, K., Shimoda, S., Hamada, Y. and Kobayashi, K. (2008) Characteristics of Ac- 
cessory Mental Foramina Observed on Limited Cone-Beam Computed Tomography Images. Journal of Endodontics, 34, 1441-1445. http://dx.doi.org/10.1016/j.joen.2008.08.033

[9] Jacobs, R., Mraiwa, N., vanSteenberghe, D., Gijbels, F. and Quirynen, M. (2002) Appearance, Location, Course, and Morphology of the Mandibular Incisive Canal: An Assessment on Spiral CT Scan. Dentomaxillofacial Radiology, 31, 322-327. http://dx.doi.org/10.1038/sj.dmfr.4600719

[10] Sawyer, D.R., Kiely, M.L. and Pyle, M.A. (1998) The Frequency of Accessory Mental Foramina in Four Ethnic Groups. Archives of Oral Biology, 43, 417-420. http://dx.doi.org/10.1016/S0003-9969(98)00012-0

[11] Naitoh, M., Yoshida, K., Nakahara, K., Gotoh, K. and Ariji, E. (2011) Demonstration of the Accessory Mental Foramen Using Rotational Panoramic Radiography Compared with Cone-Beam Computed Tomography. Clinical Oral Implants Research, 22, 1415-1419. http://dx.doi.org/10.1111/j.1600-0501.2010.02116.x

[12] Thakur, G., Thomas, S., Thayil, S.C. and Nair, P.P. (2011) Accessory Mental Foramen: A Rare Anatomical Finding. BMJ Case Reports, 2011. http://dx.doi.org/10.1136/bcr.09.2010.3326

[13] Cagirankaya, L.B. and Kansu, H. (2008) An Accessory Mental Foramen: A Case Report. Journal of Contemporary Dental Practice, 9, 98-104.

[14] Kulkarni, S., Kumar, S., Kamath, S. and Thakur, S. (2011) Accidental Identification of Accessory Mental Nerve and Foramen during Implant Surgery. Journal of Indian Society of Periodontology, 15, 70-73. http://dx.doi.org/10.4103/0972-124X.82270. 